\title{
Exploiting technology in the commercial
}

\section{world}

Charlotte Forrester and Nicola Maguire,

Bird \& Bird, PLC Counsel 3000 Global 50 law firm, London, United Kingdom

$I^{\mathrm{n}}$ $\mathrm{n}$ this article the authors explain the stages involved in the cre$I$ ation of a company and in obtaining external investment to commercialise technology developed in the laboratory. Some of the steps are illustrated by reference to a recent transaction on which they have worked, Southside Thermal Sciences Limited (STS).

\section{Early Stages}

Increasingly universities are becoming aware of their vast, untapped intellectual property resources with the potential to commercialise them and raise real value, not just for the university but also for the academic inventors. Academics are being encouraged to identify intellectual property in their laboratories that may have commercial value. Once the potential technology has been identified, how is the technology put into the marketplace?

Traditionally there are two ways that value can be achieved from an invention. The university may licence the technology and the academic will receive a payment under the university's awards to inventors scheme. Alternatively a company will be set up to commercialise the technology. This article focuses on the second route, which was the way chosen to exploit the technology now owned by STS.

What are the initial tasks that will need to be undertaken in order to get started? First you will need to prepare a business plan. This will explain to potential investors what your technology is all about, how you propose to transform the technology into a marketable product, fund your company and get your product to market. There are people you can turn to for help in this regard, from fellow academics, technology transfer departments and colleagues in business schools, to professionals who will write the plan for a fee.

\section{Southside Thermal Sciences}

STS is a company spun-out from Imperial College, London in the UK. STS was set up to commercialise a sensor coating for gas turbines which was developed by Dr Andy Heyes and Dr Jörg Feist. Udo Dengel was appointed to manage the commercial activities of the company. Their ceramic coating allows wear on the turbine blades to be monitored without having to shut down the engines to check whether the blades are deteriorating, thus improving fuel economics and maintenance costs for gas turbines [see refs.]. The company secured initial seed investment from NPI Ventures Limited (part of the Nikko group) and from the Imperial College University Challenge Fund in October 2003. It is currently looking for further investment and seeking industrial partners to collaborate on the development of its technology.

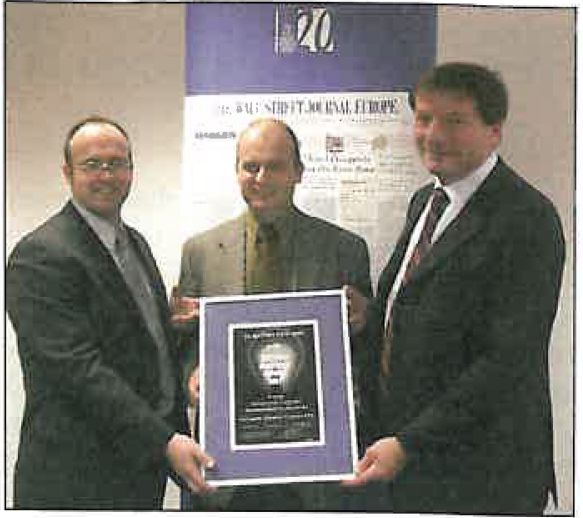

Fig. 1: Drs

Feist and Heyes receiving the European Technology Innovations Award from the editor of the Wall Street Journal Europe

There are business plan competitions you can enter which will help to raise your profile and the prize could help fund your company. STS successfully raised its profile by winning the Imperial Entrepreneurs' Challenge, Eurowards, the European Award for Entrepreneurs and the Wall Street Journal Europe 2002 Technology Innovation Award. These competitions gave STS lots of publicity that helped when it came to raising finance.

\section{Instructing professional advisers}

An initial step is to instruct professional advisers who will guide the company through the incorporation process. These will include lawyers, patent agents and accountants. Advisers will, of course, need to be paid for their services. These costs are always a burden for start-up companies and a concern for inventors wanting to commercialise their products. In choosing your advisers, seek recommendations from your institution, your colleagues and other early stage start-ups. Making a poor choice will be detrimental to your business in the long run.

Your choice of lawyers is particularly important. You may feel that the costs associated with instructing quality lawyers with experience in your sector are simply not justified. In fact, when you instruct lawyers, you are setting up what should be a genuinely beneficial relationship with your chosen firm. They should provide more than just legal advice, such as giving you the benefit of their insights into how other clients in similar sectors operate; what are good commercial terms for the types of deals you plan to enter into; the pitfalls you should look out for in certain types of deals; contacts with investors, and so on. Many professionals will offer discounts to their standard rates for start up companies, so check whether there are any arrangements from which you can benefit. STS used Bird \& Bird as they have significant experience acting for start up companies; in particular they have acted for a large number of the companies spun-out from Imperial College, London.

\section{Incorporating a company}

You will need to incorporate a company and transfer the technology to it. In most European countries companies can be quickly and cheaply set up by a lawyer, company formation agent or yourself. In the UK the Companies' Registry provides helpful guidance at www.companieshouse.com. Your lawyers may include this service at a reduced rate as part of a fee package.

Intellectual property rights are likely to be your Company's core assets and therefore you must ensure that they are properly transferred or licensed to your company. The method of transfer will depend on whether technology is patented or not. If the technology is not patented you should be wary about disclosing details of it to third parties because you will destroy your ability to obtain patent protection. This will affect the drafting of your 
business plan and the way in which you present your business to investors. Always make sure you get a signed non-disclosure agreement before handing over any confidential information and if in doubt, seek professional advice. Again, your lawyer may provide a standard draft agreement as part of their fee deal.

\section{Contacting investors}

Presentation to investors may involve your participation at technology transfer investment events or touting for opportunities to pitch at relevant conferences and angel networks. The technology transfer department at your university, your colleagues, friends and family and your lawyers may be able to help you with introductions. There are also brokers but this is a less common approach for finding initial funding of a start-up, partly due to the additional costs involved.

\section{Protecting Intellectual Property}

You must also consider how best to protect your intellectual property. If the technology is patentable you should consider making an application. A patent agent who is an expert in the relevant technology will usually be instructed to do this by the owner of the intellectual property, often the inventor's employer. Understanding who owns intellectual property is not always straightforward but your lawyers will advise you on this point.

The owner of the intellectual property will either assign the rights to the spin-out company in exchange for shares or will licence the rights in exchange for shares in the company and/or the payment of royalties. The terms are likely to need careful negotiation to ensure that the company gets a fair deal. In STS's case the relevant patents were assigned to the company.

\section{Obtaining funding}

The essential factor in a successful spin-out is obtaining funding. Without funds the company will not be able to develop its technology and grow. A good business plan and talking with investors who have experience of investing in companies using similar technology and at a similar stage of development, should help you secure that investment. Investors will see the management team as critical to the success of the venture. Many spin-out companies employ a professional manager who is experienced in the relevant sector to seek funding for them. Since the company will have no funding, the manager can be paid by being issued with shares and, as a further incentive can be granted options to acquire further shares on achievement of certain milestones, for example obtaining specified levels of funding. The length of time that it takes to obtain funding should never be underestimated. It took STS nearly a year to raise its initial investment and this is not unusual.

Once a party is interested in investing you will need to agree the investment terms. This may involve entering into heads of terms, a document in which the company, the investor and the founders of the company agree the key terms of the investment. The investor will also want to carry out some due diligence regarding the company's technology and proposed business before entering into an investment agreement. If you have not protected your ideas and intellectual property properly this will affect the value of your company and the investor's decision as to whether or not to invest. The high profile achieved by STS at an early stage through their participation in business plan competitions doubtless assisted STS in raising investment. the Brussels Stock Exchange
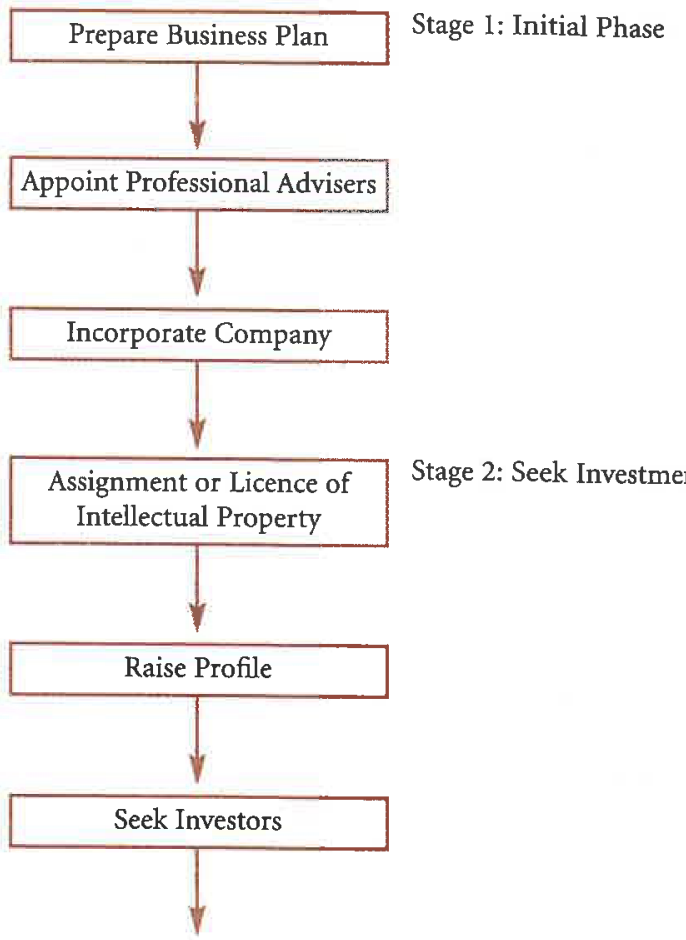

Agree Heads of Terms of

Stage 3: Confirming the Investment Investment

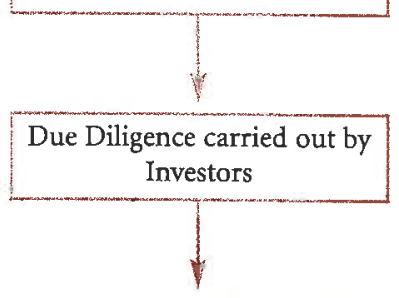

Complete Investment: agree and sign Subscription and Shareholders Agreement and adopt new Articles/By laws
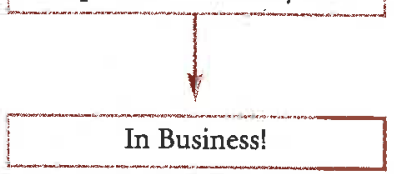

Stage 2: Seek Investment

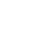

.

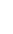




\section{Documentation}

The documentation required to implement an investment will normally comprise: a subscription and shareholders agreement; articles of association (the by-laws or rules setting out how the company is operated); share option schemes (allocating a pool of shares to reward employees and management team members); assignments and licences of intellectual property (if not already entered into); intellectual property pipeline agreements (which allow the company to take an assignment or licence of intellectual property created by the founders in the future whilst continuing to work in the university laboratory); and founders' employment or consultancy agreements.

The main document is the subscription and shareholders agreement. This sets out the terms upon which the investor will obtain shares in the company including the amount that will be paid for the shares and how many shares, and when and how the money will be paid to the company. It also includes the terms on which existing shareholders of the company (usually the investor, and the founders) will hold the shares and the way in which the company will be managed including the decisionmaking processes. In the case of STS the investors required a slightly more complicated document known as a convertible loan. The investment was lent to the company and the investors have rights to subscribe for shares in the company at any time or to require repayment of their loan.

\section{Conclusion}

Providing you identify the technology you wish to exploit and understand the steps involved, a spin-out is an effective model for the exploitation of technology. The key stages are developing the business plan, transferring the technology, finding investment and creating a business which has a good commercial basis. Expert professional advice, should be sought at each stage and is critical to getting it right. However, as with any new business, the time and effort required should not be underestimated.

\section{About the authors}

Nicola Maguire is a partner and Charlotte Forrester is an assistant in the Corporate Department at law firm Bird \& Bird. They have acted for STS and many start-up companies including a large number for Imperial College, London. They provide advice on both corporate and commercial law issues including advising on the exploitation of intellectual property through licensing, start up and joint venture companies. They also advise investors and companies on all levels of funding and on private and public acquisitions and disposals and joint ventures, many involving an international perspective.

\section{References}

Choy K.L., Feist J.P., Heyes A.L., Mei J. 2000, 'Microstructure and Thermoluminescent Properties of ESAVD Produced Eu Doped Y2O3-ZrO2 Coatings', Surface Engineering 16;

Feist J.P., Heyes A.L. 2000, 'Europium Doped YSZ for High Temperature Phosphor Thermometry', Proc. Instn. Mech. Engrs. Part L 214: 7-12;

Feist J.P., 2001, 'Development of Phosphor Thermometry for Gas Turbines', $\mathrm{PhD}$ thesis, Imperial College London.;

Choy K.L., Heyes A.L., Feist, J.P., 'Thermal barrier coating with thermoluminescent indicator material embedded therein', European Patent 1105550 .

\section{Competitive aspects of a probe storage}

\section{technology}

Eric Ruetsche,

IBM Zurich Research, Rueschlikon, Switzerland

$P^{\text {robe storage technology has been pioneered by Gerd Binnig }}$ $P$ and Peter Vettiger who developed the concept based on AFM activities in IBM Zurich Research. The basic concept uses a matrix of micro-machined cantilevers to write and read indentations in a polymer material [1]. The cantilevers are bonded to a CMOS chip that holds an analogue sensing unit per cantilever and a multiplexer that transfers the data to the main sensor and control component. A magnetically actuated $\mathrm{x} / \mathrm{y}$ scanner moves the storage media cantilevers relative to the cantilevers (see Figure 1). A mass-balanced design protects the media from shock in the $x / y$ direction. In a single-lever test system the thermomechanical read/write mechanism has demonstrated a storage density of $641 \mathrm{Gbit} / \mathrm{in} 2$ at raw bit-error rates of $10-4[2,3]$. Raw error rates of this order of magnitude are typical for magnetic recording. Standard error correction schemes can be used to get to the error rates required for today's applications. The system architecture, control and error correction codes are currently being developed to demonstrate a fully functional storage system. MEMS components have been fabricated and assembled and are incorporated into a first small-scale prototype that serves as a test platform for the channel and control electronics built on a dedicated printed circuit board. In parallel to the technical developments a commercial evaluation is performed to validate the competitiveness and market attractiveness of the technology against the most successful non-volatile memory technologies today: magnetic hard disc drive (HDD) and Flash. (We will use the term storage for any non-volatile memory)

\section{Assessing a technology}

The attractiveness of a technology can only be analysed by looking at the attractiveness of derived products for particular applications and markets. In a commercial enterprise the business case will be analysed to evaluate the attractiveness of any

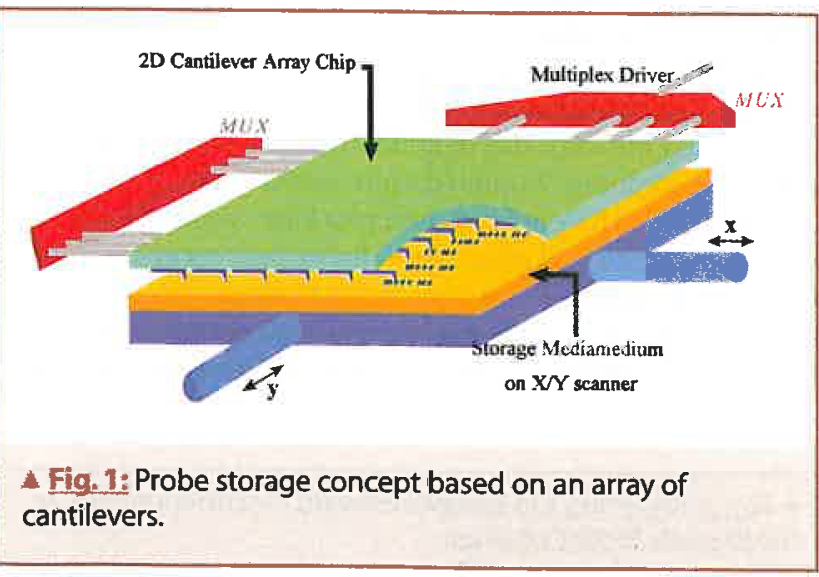

